\title{
O uso de testes de hipótese para aferir a existência de diferença no desempenho de egressos do Ensino Médio na tarefa de relacionar a Física com o cotidiano do
} trânsito

\author{
Patrick Alves Vizzotto*, Luiz Fernando Mackedanz**
}

\section{Resumo}

Apresenta-se os resultados de uma pesquisa que investigou se egressos do Ensino Médio relacionam a Física escolar com o cotidiano do trânsito. Para tal, foi aplicado um questionário com questões de Física aplicadas a este contexto, e posteriormente, testes de hipótese foram realizados, a fim de verificar se grupos com características opostas dessa mesma amostra apresentaram desempenhos estatisticamente diferentes entre si. Foram testadas hipóteses de igualdade de médias entre gênero, idade, realidade escolar, experiência com veículos e nível educacional atual, por meio do Teste $U$ de Mann-Whitney. Notou-se que participantes que concluíram o Ensino Médio em escolas particulares, assim como os que já haviam dirigido até o momento da pesquisa, obtiveram desempenhos estatisticamente maiores do que o grupo oposto. Tais constatações corroboram com a concepção de que a qualidade do ensino, a consideração dos conhecimentos prévios dos estudantes e as experiências vivenciadas por cada indivíduo, podem ser fatores de impacto na aprendizagem, potencializando uma maior retenção de conceitos físicos em egressos da educação básica e a possibilidade de desenvolver uma visão crítica do seu cotidiano, preceitos básicos de uma Alfabetização Científica.

Palavras-chave: Ensino de Física. Física aplicada ao trânsito. Pesquisa quantitativa; Alfabetização Científica.

* Doutor em Educação em Ciências (UFRGS). Bolsista de Pós-doutorado (PNPD/CAPES) da UNIVATES. E-mail: patrick.vizzotto@gmail.com

* Doutor em Ciências (UFRGS). Professor Associado do Instituto de Matemática, Estatística e Física da FURG. Docente do Programa de Pós-graduação em Educação em Ciências (FURG). E-mail: luismackedanz@furg.br

Recebido em: 26/07/2019 - Aceito em: 30/09/2019.

https://doi.org/10.5335/rbecm.v2i2.9904 


\section{Introdução}

A Física escolar tem como um dos seus objetivos possibilitar o surgimento de habilidades e competências, para que os alunos possam interpretar a natureza e 0 funcionamento de dispositivos tecnológicos presentes em suas vidas. Ou seja, visa preparar os indivíduos para protagonizar diferentes situações cotidianas, em que $o$ conhecimento das relações de causa e efeito de suas ações permita a possibilidade de uma tomada de decisões crítica e responsável.

Para isso, de acordo com a visão de aprendizagem de Ausubel (2003), é importante que as aulas construam relações entre os conteúdos de Física e os conhecimentos já existentes na estrutura cognitiva dos estudantes. Uma das maneiras de acessar esses saberes prévios é através da contextualização. Assim, acredita-se que compreender o funcionamento de fenômenos físicos a partir de uma situação presente no cotidiano dos alunos pode auxiliar na retenção de conhecimentos à longo prazo.

Espera-se da Educação Básica que, ao concluí-la, o egresso tenha adquirido certo nível de Alfabetização Científica (HURD, 1958), de modo que a sua interpretação de mundo possa ser pautada também pela criticidade de sua análise. Isso significa que o conhecimento escolar pode auxiliar nessa formação crítica, na qual os conteúdos da disciplina de Física (e de outras disciplinas) têm papel fundamental no aprimoramento da leitura do mundo. Para o caso das Ciências da Natureza, os saberes podem atuar na explicação de grande parte dos fenômenos cotidianos e aplicações tecnológicas, abordagem defendida pela estratégia da contextualização (RICARDO, 2005).

O tema trânsito está presente no cotidiano da maioria dos estudantes, seja na condição de pedestres, seja na de passageiros. Basta sair de casa para inserir-se nesta realidade, na qual, percebe-se a presença de inúmeros fenômenos físicos ali aplicados. Por isso, defendemos que esta temática é um espaço frutífero para se buscar formas de aliar os temas de Física com aplicações cotidianas.

No Brasil, a média de mortes no trânsito nos últimos 7 anos foi de aproximadamente 41.900 pessoas (BRASIL, 2018). Essas fatalidades são causadas, majoritariamente, por déficits na educação para o trânsito (NEGRINI NETO; KLEINUBING, 2012). Esses números ressaltam a importância de se compreender significativamente a dinâmica do trânsito, uma vez que são as ações dos condutores que podem salvar ou subtrair vidas, pois a imprudência e negligência causadas pela falta de consciência 
de suas ações são as maiores causadoras de acidentes, mais do que problemas de engenharia veicular e viária, ou questões ligadas às leis de trânsito.

Diante dessa realidade, a escola se mostra como um canal impar na promoção de discussões sobre valores fundamentais para a vivência dentro do trânsito, proporcionando ao Ensino de Física a oportunidade de desvendar o funcionamento de dispositivos veiculares e fenômenos físicos aplicados a este cotidiano, sendo tal objetivo, de modo geral, orientado pelo Ministério da Educação (BRASIL, 1996; 2000; 2019).

Como a orientação de um ensino para a vida está presente nesses documentos desde a criação da Lei de Diretrizes e Bases da Educação Nacional, lei 9.394 (BRASIL, 1996), espera-se que os indivíduos que iniciaram seus estudos após a vigência desta orientação possam ter vivenciado um ensino com maiores momentos de contextualização dentro de situações presentes em suas vidas, e não mais um ensino predominantemente propedêutico e fragmentado.

Nesse sentido, mostra-se pertinente investigar o quanto do conhecimento escolar é aproveitado ou relacionado ao cotidiano do estudante depois dele sair do Ensino Médio. Assim, a pergunta que guiou este estudo questiona se "os egressos do Ensino Médio conseguem fazer uso dos seus saberes para compreender de maneira cientificamente adequada situações de Física aplicada ao trânsito?”. Para isso, realizou-se uma pesquisa com objetivo de verificar as relações entre a Física e o trânsito de egressos do Ensino Médio por meio de um questionário de conhecimentos.

Foi elaborado um instrumento com 10 perguntas de múltipla escolha, semelhantes aos itens do Exame Nacional do Ensino Médio (ENEM), das quais, após respondidas, gerou-se um somatório de acertos para cada entrevistado. Neste artigo, buscou-se verificar, através de Testes de Hipótese, se há relação entre o desempenho dos participantes e seus dados de caracterização, como gênero, idade, formação escolar, experiência com veículos e nível educacional.

Os participantes, egressos do Ensino Médio, foram alunos de Cursos de Primeira Habilitação de Centros de Formação de Condutores de uma cidade do interior do Rio Grande do Sul. Havia como pré-requisitos para participação, a conclusão do Ensino Médio e idade entre 18 e 30 anos. Este limite de idade foi imposto devido ao foco delimitador desta análise, que busca investigar egressos que estudaram o Ensino Médio já dentro da vigência da Lei de Diretrizes e Bases da Educação, iniciada em 1996. 
$\mathrm{O}$ artigo está estruturado da seguinte maneira: primeiramente, busca-se justificar o trabalho dentro do referencial teórico da área. Em seguida, realiza-se uma revisão sobre os testes de hipóteses dentro da estatística inferencial (PASQUALI; PRIMI, 2003; HAIR, et. al, 2005; KIRSTEN; RABAHY, 2006; PEREIRA, 2006), a fim de situar o leitor na abordagem utilizada, para estabelecer as deduções concluídas nesta pesquisa. Em um terceiro momento, os aspectos metodológicos da investigação são detalhados, desde a construção do questionário até os procedimentos de coleta e análise dos dados. Na sequência, os resultados são apresentados e discutidos à luz do referencial teórico, finalizando o trabalho com as considerações sobre o estudo e as perspectivas para a continuidade da pesquisa.

\section{Fundamentos metodológicos}

Teste de Hipótese é um procedimento estatístico utilizado para aferir determinados parâmetros que são desconhecidos em uma população. São constituídos de alternativas que são submetidas a testes. Uma população tem uma amostra retirada e através da aplicação de teoria de probabilidades é possível tirar conclusões em relação a ela (PASQUALI; PRIMI, 2003).

Um teste de hipótese analisa duas proposições opostas sobre uma determinada população, denominadas de hipótese nula (H0) e hipótese alternativa (HA). A hipótese nula é a afirmação que está sendo testada. É o que se considera como verdade para a elaboração do teste, ou seja, é o fato que se deseja testar. Geralmente, ela é uma declaração de nenhuma implicação ou nenhuma diferença sobre o comportamento da amostra. A hipótese alternativa, por sua vez, é a declaração antagônica que se aceitaria como verdadeira, caso a hipótese nula seja rejeitada.

Antes de realizar um teste de hipótese, ele deve ser planejado por meio de 7 etapas (PIRES, 2000), citadas a seguir: 1. Pelo contexto do problema, identificar o parâmetro de interesse; 2. Especificar a hipótese nula; 3. Especificar uma hipótese alternativa apropriada; 4. Escolher o nível de significância $\square$; 4. Escolher uma estatística de teste adequada; 5 . Fixar a região crítica do teste; 6 . Recolher uma amostra e calcular o valor observado da estatística de teste; 7 . Decidir sobre a rejeição ou não de H0.

Com base nos dados da amostra, o teste determina se a hipótese nula deve ser rejeitada ou aceita. Isto é decidido observando um determinado coeficiente ( $\mathrm{p}$-valor) 
que consiste em um ponto limite definido com base no nível de erro de decisão em que a análise está sendo submetida. Geralmente, admite-se $1 \%$ ou $5 \%$ de erro da medida, o que proporciona, respectivamente, uma certeza de $99 \%$ ou $95 \%$ na decisão de aceitar ou não a rejeição da hipótese nula. Isto é, um p-valor de 0,05 significa que existe uma probabilidade de $5 \%$ de se obter esse resultado por acaso na situação de não haver uma diferença real entre os dois grupos estudados. Se o p-valor for menor ou igual ao nível de significância, então, sugere-se rejeitar a hipótese nula. Tanto o ponto limite do p-valor, quanto a fórmula utilizada para calculá-lo, dependerá do teste escolhido, sendo valores tabelados pela literatura da área (HAIR et al., 2005).

O teste escolhido dependerá de fatores relacionados com o tipo de análise que se deseja realizar e o comportamento dos dados obtidos. Os testes paramétricos necessitam que os dados obedeçam à tendência normal da curva de distribuição (distribuição Gaussiana). Os conjuntos de dados também necessitam possuir variâncias consideradas iguais, ao contrário dos testes não-paramétricos, que são alternativas de uso para quando os dados não seguem a referida tendência à normalidade (NOBRE, 2012).

Todos os testes utilizados nessa pesquisa para aferição das caraterísticas dos dados tem como base a Teoria Clássica de Testes. Para determinar se a amostra possui dados que obedecem a uma curva normal é necessário realizar um teste de normalidade. Para tal, foi utilizado o teste de Kolmogorov-Smirnov. Esse, se utiliza da comparação entre dois grupos independentes, verificando a concordância entre duas distribuições acumuladas. Para interpretar o resultado para o teste de Kolmogorov-Smirnov, basta observar o p-valor de significância. Esse valor, para uma significância de $95 \%$ deve possuir um número maior que 0,05 para ser considerada uma distribuição normal, ou seja, toda vez que o teste apresentar valor $p<0,05$, significa fuga de normalidade.

Para comparação entre dois grupos é necessário que as suas variâncias também tendam à igualdade, sendo necessário aplicar outro teste, o Teste de Levene. Ele testa a homogeneidade de variância, ou seja, testa se há ou não variabilidade semelhante entre os grupos testados. Para os dados dessa pesquisa, no caso de as amostras apresentarem os pré-requisitos necessários para a realização de testes paramétricos, realiza-se o Teste t para amostras independentes; caso contrário, pode-se utilizar o Teste U de Mann-Whitney como opção de teste não-paramétrico. 
O Teste t para amostras independentes consiste na comparação de médias entre dois grupos. Em todo Teste t, é necessário observar também o p-valor, pois dessa forma, se poderá verificar se a diferença ocorre com $\mathrm{p}<0,05$, rejeitando a hipótese nula ou se consiste apenas em um valor $\mathrm{p}>0,05$, aceitando assim, a hipótese nula. Por sua vez, o Teste U de Mann-Whitney é utilizado quando se tem uma análise não-paramétrica de dados. Basicamente, esse teste verifica se há evidências para acreditar que valores de um grupo são superiores aos valores de um segundo grupo. Para analisar a hipótese, o teste de Mann-Whitney cria um ranking de todos os casos, independente do grupo a que a média pertença e depois compara estes rankings entre cada grupo. Para uma explicação mais detalhada, recomendamos a leitura de livros-texto da Estatística Inferencial (PASQUALI; PRIMI, 2003; HAIR, et. al, 2005).

\section{Metodologia}

No caso dessa investigação, os testes de hipótese analisaram escores de desempenho advindos de uma das medidas de tendência central, obtidas através da aplicação de um questionário (VIZZOTTO; MACKEDANZ, 2019). Em específico, foi considerada a média do somatório de acertos de cada participante da amostra. $\mathrm{O}$ instrumento de pesquisa foi elaborado pelos autores, contendo 10 questões conceituais de múltipla escolha, criadas com base no estilo das questões utilizadas pelo Exame Nacional do Ensino Médio (ENEM). O processo de validação do questionário contou com a avaliação de professores doutores da área de Ensino de Física (validade de conteúdo) e também com um teste piloto para avaliar a sua consistência interna. $\mathrm{O}$ índice de consistência interna (teste Alfa de Cronbach), que atesta a fidedignidade do instrumento, obteve um valor final de 0,74 . O processo de validação sugeriu retirar da análise 2 das 10 questões, a fim de aumentar o coeficiente Alfa de Cronbach para o valor citado. Portanto, as questões 1 e 4 do instrumento não foram consideradas para a estatística de acertos e erros.

Conforme referido, os pré-requisitos para participar da pesquisa consistiam na conclusão do Ensino Médio e idade compreendida entre 18 e 30 anos. A coleta de dados aconteceu em Cursos de Primeira Habilitação de autoescolas de uma cidade do interior do Rio Grande do Sul. A pesquisa contou com a participação de um total de 202 egressos do Ensino Médio, estudantes de autoescolas. 
O questionário também coletou dados de caracterização dos respondentes, tais como gênero, idade, tipo de escola em que concluiu a educação básica (escola pública ou particular), se possuía experiência na condução de veículos e formação escolar atual (se havia ingressado ou não na graduação após o Ensino Médio). Tais características foram comparadas com o índice de acertos de cada participante, a fim de verificar se era possível perceber diferença de acertos entre grupos dicotômicos, como por exemplo, homens e mulheres, ou formados em escola pública e formados em escola particular.

Os dados foram compilados e analisados através do software Statistical Package for the Social Sciences - SPSS, versão 23 para Windows. Cabe ressaltar que se optou por utilizar as tabelas e gráficos gerados pelo próprio software, a fim de garantir a confiabilidade dos resultados apresentados, o que justifica alguns deles encontrarem-se na língua inglesa.

Primeiramente, para saber qual teste de hipótese utilizar foi necessário constatar se o índice de acertos geral obedecia à curva normal (distribuição Gaussiana). Para isso foi utilizado o teste de Kolmogorov-Smirnov. Esse teste avalia a normalidade de variáveis quantitativas. Para interpretar a sua saída do software estatístico, observa-se o p-valor de significância bilateral. Esse valor, para uma significância de $95 \%$, deve possuir um número maior que 0,05 para ser considerado uma distribuição normal, ou seja, valores de p-valor menores que 0,05 para o teste de Kolmogorov-Smirnov indicam fuga de normalidade (PEREIRA, 2006).

Conforme se pode observar no Quadro 1, no teste, o p-valor de 0,001 constata uma fuga da normalidade para o índice de acertos dos estudantes. Dessa forma, não é recomendado realizar testes paramétricos nos dados da pesquisa. Sendo assim, os testes de hipóteses realizados no decorrer da análise de dados obedecerão ao caráter de testes não-paramétricos, conforme orienta a literatura da área (COSTA, 2006; HAIR et. al., 2005; HILL; HILL, 2005; KIRSTEN; RABAHY, 2006; PEREIRA, 2006). 
Quadro 1: Saída do software estatístico para o Teste de Kolmogorov-Smirnov

One-Sample Kolmogorov-Smirnov Test

\begin{tabular}{|c|c|c|}
\hline & & $\begin{array}{c}\text { acertos_por_ } \\
\text { pessoa }\end{array}$ \\
\hline$N$ & & 202 \\
\hline \multirow[t]{2}{*}{ Normal Parameters ${ }^{a, b}$} & Mean & 3,92 \\
\hline & Std. Deviation & 1,726 \\
\hline \multirow[t]{3}{*}{ Most Extreme Differences } & Absolute & 135 \\
\hline & Positive & 130 \\
\hline & Negative &,- 135 \\
\hline Kolmogorov-Smirnov Z & & 1,920 \\
\hline Asymp. Sig. (2-tailed) & &, 001 \\
\hline
\end{tabular}

a. Test distribution is Normal.

b. Calculated from data.

Fonte: autores.

Justificado o uso de um teste não-paramétrico, passamos a utilizar o Teste U de Mann-Whitney. Sendo assim, a seguir apresenta-se uma série de cinco testes realizados com o objetivo de verificar a hipótese de relações entre os índices de acertos dos estudantes e as variáveis de caracterização dos entrevistados.

Um dos pré-requisitos para se realizar um teste não-paramétrico é a igualdade (homogeneidade) de variâncias. Para constatar isso, conforme referido, aplicou-se o Teste de Levene em cada conjunto de dados testado. Segundo Pereira (2006), para interpretar a saída do software estatístico para este teste, se deve observar o p-valor da significância bilateral do teste. Se a significância for menor ou igual a 0,05 , considera-se que deve ser rejeitada a igualdade das variâncias; logo, se a significância do teste for maior que 0,05 , considera-se as variâncias como iguais.

Sendo assim, para cada teste de hipótese apresentado, inicialmente se testará a homogeneidade de variâncias e logo após, se realizará o teste não-paramétrico. 


\section{Resultados}

\section{Teste de hipótese para gênero}

Este teste de hipótese teve por objetivo observar se há diferença na média de distribuição de acertos dos estudantes do sexo masculino e feminino, ou seja, se algum dos dois grupos apresentou melhor desempenho na relação dos conceitos Físicos aplicados ao trânsito.

Quadro 2: Saída do software estatístico para o Teste de Levene

Test of Homogeneity of Variances

Acertos
\begin{tabular}{|c|c|c|c|}
\hline $\begin{array}{l}\text { Levene } \\
\text { Statistic }\end{array}$ & df1 & df2 & Sig. \\
\hline 1,086 & 1 & 200 &, 299 \\
\hline
\end{tabular}

Fonte: autores.

No caso dos dados configurados para o Teste de hipótese para gêneros, o valor da significância é 0,299 , ou seja, maior que 0,05 , mantendo a hipótese nula de que as variâncias são iguais (homogêneas).

Para analisar o resultado do teste é necessário observar o nível de significância bilateral/bicaudal apresentado. O teste bicaudal tem o objetivo de testar apenas se as proporções são iguais ou diferentes e não estabelecer qual delas é maior ou menor (KIRSTEN; RABAHY, 2006). Para verificar quem obteve maior ou menor desempenho, basta observar, em cada quadro, a média de acertos de ambos os grupo.

Para o teste de hipótese para gêneros os dados foram tabulados de modo que o software considerasse a diferenciação dos gêneros como $1 \mathrm{e} 2$, atribuindo o número 1 ao Feminino e 2 ao Masculino.

A seguir são apresentados, no Quadro 3, os resultados derivados das análises do Teste U, no qual verificamos que o nível de significância bilateral observado é de 0,444 , ou seja p-valor maior que 0,05 , o que não permite rejeitar a hipótese nula em que afirma que as médias das duas amostras são as mesmas para os dois grupos. 
Esse resultado possibilita concluir que as discrepâncias no escore total de acertos e erros não são influenciadas pelo gênero do respondente.

Quadro 3: Saída do software estatístico para o Teste U

\begin{tabular}{|c|c|c|c|c|c|c|}
\hline \multicolumn{5}{|c|}{ Ranks } & \multicolumn{2}{|c|}{ Test Statistics $^{a}$} \\
\hline & Gênero & $\mathrm{N}$ & Mean Rank & Sum of Ranks & & Acertos \\
\hline \multirow[t]{3}{*}{ Acertos } & 1 & 122 & 104,01 & 12689,00 & \multirow{4}{*}{$\begin{array}{l}\text { Mann-Whitney U } \\
\text { Wilcoxon W } \\
\text { Z } \\
\text { Asymp. Sig. (2-tailed) }\end{array}$} & 4574,000 \\
\hline & 2 & 80 & 97,68 & 7814,00 & & 7814,000 \\
\hline & Total & 202 & & & &,- 765 \\
\hline & & & & & & ,444 \\
\hline
\end{tabular}

Hypothesis Test Summary

\begin{tabular}{|clrl|}
\hline \multicolumn{1}{|c|}{ Null Hypothesis } & \multicolumn{1}{c|}{ Test } & Sig. & Decision \\
\hline 1 & $\begin{array}{l}\text { Independent- } \\
\text { The distribution of Acertos is the } \\
\text { same across categories of Gênero. }\end{array}$ & $\begin{array}{l}\text { Samples } \\
\text { Mann- } \\
\text { Whitney U } \\
\text { Test }\end{array}$ & $444 \begin{array}{l}\text { Retain the } \\
\text { null } \\
\text { hypothesis. }\end{array}$ \\
\hline
\end{tabular}

Asymptotic significances are displayed. The significance level is ,05.

Fonte: autores.

O Quadro 4 apresenta um resumo paralelo das medidas de tendência central e dispersão para os estudantes masculinos e femininos. Nota-se que as estudantes do grupo feminino (122 participantes) obtiveram um desempenho superior aos estudantes masculinos (80 participantes), mesmo que esse desempenho não signifique uma diferença estatística na distribuição das médias entre os dois grupos. Essa diferença é pequena, uma vez que se pode notar que os valores de mediana são os mesmos para os dois grupos. 
Quadro 4: Medidas de tendência central e dispersão para gêneros

\section{Statistics}

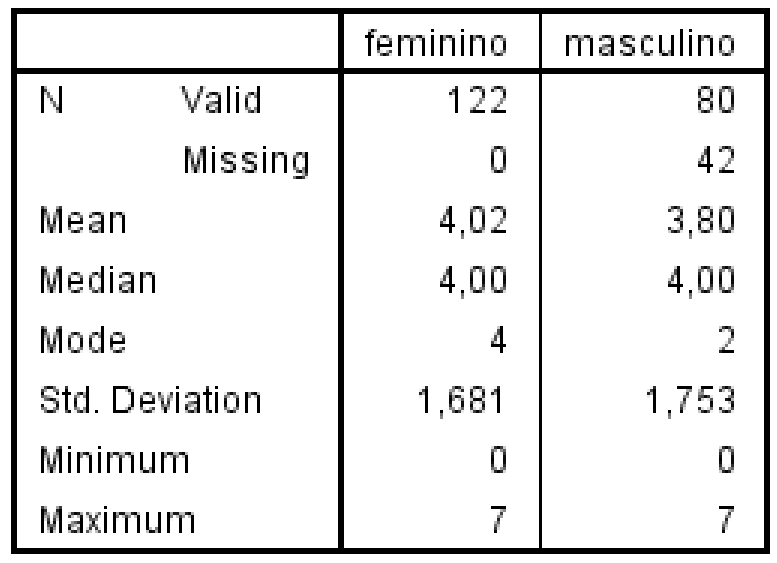

Fonte: autores.

De forma geral, $8,2 \%$ das participantes do grupo feminino tiveram um número máximo de acertos ( 7 das 8 questões analisadas), enquanto que esse escore de acertos fez parte apenas de 3,3\% dos estudantes do gênero masculino. Já para o número mínimo (zero acertos), os percentuais foram de $0,8 \%$ do gênero feminino e $2,5 \%$ do masculino.

Apesar dessas diferenças encontradas descritivamente, ao aplicar o teste de hipótese, verificou-se que, com uma significância de $95 \%$ de certeza, não há diferença entre um gênero e outro na distribuição de acertos.

\section{Teste de hipótese para escolaridade}

O objetivo desse teste foi verificar a hipótese nula de que estudantes que concluíram seus estudos em escolas públicas possuem o mesmo desempenho que estudantes que concluíram o Ensino Médio em escolas particulares.

Como padrão, foi realizado o teste de homogeneidade de variâncias para os dados configurados para o presente teste. 
Quadro 5: Saída do software estatístico para o Teste de Levene

Test of Homogeneity of Variances

\section{Acertos}

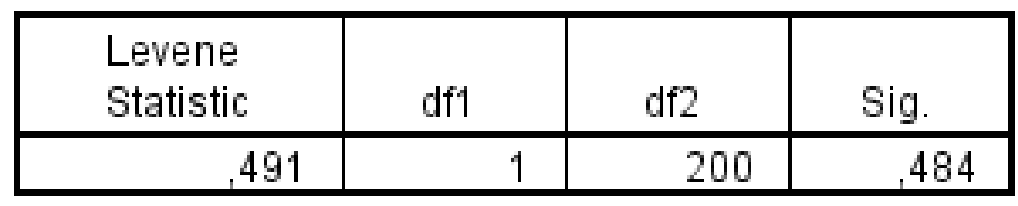

Fonte: autores.

Para realizar o Teste U foram codificadas as variáveis como: 1 para Ensino Médio concluído em escola pública e 2 para escola particular. Conforme se pode notar no quadro 6, 175 estudantes concluíram em escola pública e somente 27 em escola particular, porém, mesmo em menor número, essa minoria apresentou um melhor desempenho, conforme se pode observar no rank médio do quadro apresentado.

No Teste de Levene (Quadro 5) o valor da significância é 0,484, ou seja, maior que 0,05 , mantendo a hipótese nula de que as variâncias são iguais. A seguir apresentamos os Quadros derivados do software para o Teste U dessas variáveis.

Quadro 6: Saída do software estatístico para o Teste U

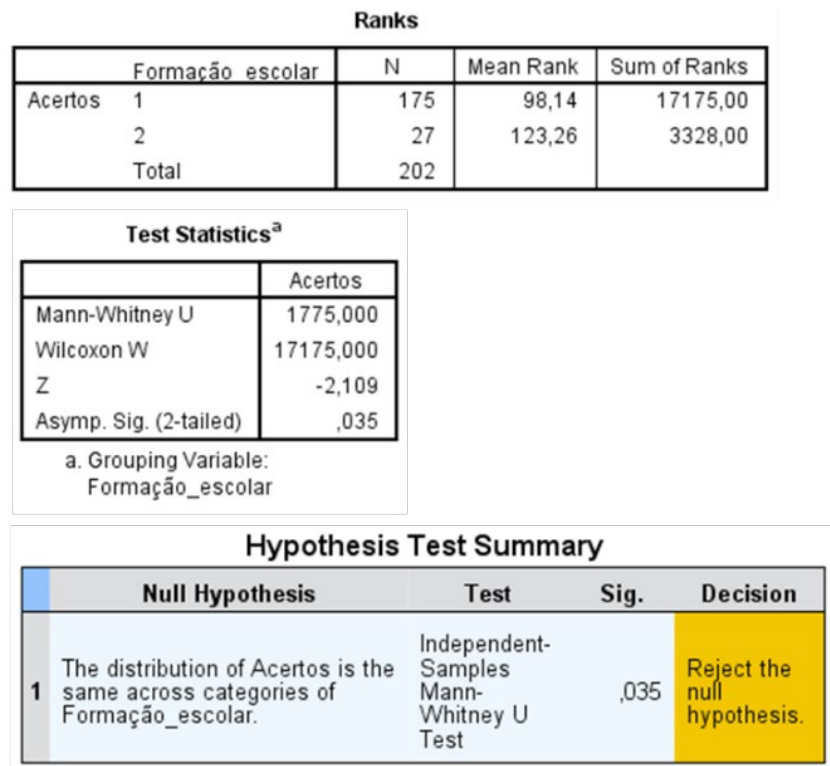

Asymptotic significances are displayed. The significance level is ,05.

Fonte: autores. 
O nível de significância bilateral observado é de 0,035 , ou seja, p-valor menor que 0,05 , o que sugere rejeitar a hipótese nula na qual afirma que as médias das duas amostras são as mesmas para os dois grupos.

Dessa forma, podemos afirmar que houve diferença estatística entre os questionários respondidos por estudantes que concluíram o Ensino Médio em escolas particulares e os que concluíram em escolas públicas, ou seja, o fator "escola" é uma variável importante para explicar a diferença de desempenho entre os estudantes da pesquisa.

Observando os dois grupos descritivamente, a diferença entre eles visivelmente aparece ao observarmos o quantitativo das medidas de mediana e também de moda. Mesmo que a diferença entre medianas seja somente de um acerto, a diferença entre modas (5 para escola particular e 2 para escola pública) demonstra uma considerável discrepância entre os dois grupos analisados.

Quadro 7: Medidas de tendência central e dispersão para diferença de escolaridade

Statistics

\begin{tabular}{|l|r|r|}
\hline & $\begin{array}{c}\text { Escola_partic } \\
\text { ular }\end{array}$ & $\begin{array}{r}\text { Escola_públic } \\
\text { a }\end{array}$ \\
\hline $\mathrm{N} \quad$ Valid & 27 & 175 \\
Mean & 148 & 0 \\
Median & 4,56 & 3,82 \\
Mode & 5,00 & 4,00 \\
Std. Deviation & 5 & 2 \\
Minimum & 1,717 & 1,711 \\
Maximum & 0 & 0 \\
\hline
\end{tabular}

Fonte: autores.

O número de estudantes que obtiveram $0 \%$ de desempenho no grupo de estudantes vindos de escolas públicas é quase três vezes maior que os estudantes formados por escolas particulares. De forma inversa, o índice de estudantes que obtiveram 7 dos 8 acertos do questionário é quase três vezes maior no grupo dos estudantes oriundos de escola particular.

Mais do que aproveitar esse resultado para discutir o nível de ensino da escola pública, ele mantém as observações retiradas das análises de desempenho ao longo 
dos últimos anos no ENEM, nas quais esse comportamento repete-se. No entanto, a análise dos percentuais também pode ser questionada, uma vez que o número de alunos oriundos de escolas públicas que realizou o teste equivale a $87 \%$ da amostra. Por exemplo, considerando o número absoluto de questionários, temos 14 indivíduos com 7 acertos ( $71 \%$ da escola pública) e 26 com 6 acertos ( $89 \%$ de escola pública). No outro extremo, 4 indivíduos não obtiveram acerto algum (75\% de escola pública) e 8, todos da escola pública, alcançaram 1 acerto. Essa possibilidade ressalta a importância de se realizar outros estudos que repliquem os testes realizados em grupos semelhantes à amostra pesquisada.

\section{Teste de hipótese para experiência com veículos}

Esse teste teve por objetivo observar se o indivíduo que teve contato como condutor de um veículo, seja automóvel, moto ou similar, antes de realizar o processo de primeira habilitação, apresentou um desempenho diferente do que os que nunca dirigiram. A hipótese nula versa que a distribuição de acertos entre os dois grupos é a mesma. A seguir é apresentado o teste de homogeneidade de variâncias e na sequência os resultados do Teste U:

Quadro 8: Saída do software estatístico para o Teste de Levene

Test of Homogeneity of Variances

Acertos
\begin{tabular}{|c|c|c|c|}
\hline $\begin{array}{l}\text { Levene } \\
\text { Statistic }\end{array}$ & df1 & df 2 & Sig. \\
\hline .172 & 1 & 200 &, 678 \\
\hline
\end{tabular}

Fonte: autores.

O valor da significância do Teste de Levene é 0,678 , ou seja, maior que 0,05 , mantendo a hipótese nula de que as variâncias são iguais (Quadro 8).

Para a análise, se codificou os dados com o número 1 para os estudantes que nunca haviam dirigido até o momento da pesquisa e 2 para os que já haviam tido experiência com veículos. Conforme se pode observar no Quadro 9, dos 202 participantes, 110 nunca haviam dirigido e os outros 92 já possuíam experiência como motoristas. 
Quadro 9: Saída do software estatístico para o Teste U

Ranks

\begin{tabular}{|rl|r|r|r|}
\hline & Experiência_com_veículo & N & Mean Rank & Sum of Ranks \\
\hline Scertos & 1 & 110 & 89,15 & 9807,00 \\
& 2 & 92 & 116,26 & 10696,00 \\
& Total & 202 & & \\
\hline
\end{tabular}

Test Statistics ${ }^{a}$

\begin{tabular}{|l|r|}
\hline & \multicolumn{1}{|c|}{ Acertos } \\
\hline Mann-Whitney U & 3702,000 \\
Wilcoxon W & 9807,000 \\
Z & $-3,331$ \\
Asymp. Sig. (2-tailed) &, 001 \\
\hline
\end{tabular}

a. Grouping Variable:

Experiência_com_veículo

S

Hypothesis Test Summary

\begin{tabular}{|c|c|c|c|c|}
\hline & Null Hypothesis & Test & Sig. & Decision \\
\hline 1 & $\begin{array}{l}\text { The distribution of Acertos is the } \\
\text { same across categories of } \\
\text { Experiência_com_veiculos. }\end{array}$ & $\begin{array}{l}\text { Independent- } \\
\text { Samples } \\
\text { Mann- } \\
\text { Whitney U } \\
\text { Test }\end{array}$ & ,001 & $\begin{array}{l}\text { Reject the } \\
\text { null } \\
\text { hypothesis. }\end{array}$ \\
\hline
\end{tabular}

Asymptotic significances are displayed. The significance level is ,05.

Fonte: autores.

O nível de significância bilateral observado é de 0,001 , ou seja, p-valor menor que 0,05 , o que permite rejeitar a hipótese nula. Assim, se pode afirmar que há diferença entre os questionários respondidos por estudantes que já haviam tido experiências com veículos, antes mesmo de passar pelo processo da primeira habilitação, em comparação aos estudantes que nunca haviam dirigido.

Nota-se, observando o Quadro 9, que as médias do grupo de número 2 possui um escore superior quando comparado com o grupo 1, ou seja, há conexão entre bons desempenhos e experiências com veículos. É sugerida, também em estudos posteriores, aferir a causalidade dessa correlação.

Com essa constatação, pode-se inferir que o fator "experiência/vivência/conhecimento experiencial" é notável na hora de estabelecer relações entre conceitos físicos e as situações adversas que podem surgir no cotidiano do trânsito.

Através do Quadro 10, pode-se observar os valores de tendência central para esses dois grupos, cujas diferenças entre médias, medianas e modas se mostram evidentes, principalmente ao se comparar as modas ( 2 acertos para o grupo de estudantes sem experiência e 5 para os estudantes que já dirigiram) o que corrobora com o teste de hipótese e demonstra o melhor desempenho do grupo 2 . 
Quadro 10: Medidas de tendência central e dispersão para experiência com veículos

Statistics

\begin{tabular}{|c|c|c|c|}
\hline & & Nunca_dirigiu & Já_dirigiu \\
\hline \multirow[t]{2}{*}{$\mathrm{N}$} & Valid & 110 & 92 \\
\hline & Missing & 0 & 18 \\
\hline \multicolumn{2}{|c|}{ Mean } & 3,57 & 4,34 \\
\hline \multicolumn{2}{|c|}{ Median } & 3,50 & 5,00 \\
\hline \multicolumn{2}{|c|}{ Mode } & 2 & 5 \\
\hline \multicolumn{2}{|c|}{ Std. Deviation } & 1,711 & 1,659 \\
\hline \multicolumn{2}{|c|}{ Minimum } & 0 & 0 \\
\hline \multicolumn{2}{|c|}{ Maximum } & 7 & 7 \\
\hline
\end{tabular}

Fonte: autoria própria.

Como podemos verificar, os valores de tendência central esclarecem o motivo de se rejeitar a hipótese nula.

\section{Teste de hipótese para nivel escolar atual}

Esse teste observou o nível de escolaridade atual dos entrevistados. Procurou-se saber se além do nível escolar mínimo para participação da pesquisa (Ensino Médio completo), quais deles já haviam ingressado na graduação e, se aqueles que estavam na academia apresentaram desempenhos diferentes do grupo dos que ainda não haviam ingressado na graduação. Para tal, realizou-se em um primeiro momento, o teste de hipótese para variâncias iguais.

Quadro 11: Saída do software estatístico para Teste de Levene.

Test of Homogeneity of Variances

Acertos

\begin{tabular}{|l|r|r|c|}
\hline $\begin{array}{l}\text { Levene } \\
\text { Statistic }\end{array}$ & $\mathrm{df1}$ & $\mathrm{df} 2$ & Sig. \\
\hline 1,012 & 1 & 193 &, 316 \\
\hline
\end{tabular}

Fonte: autores. 
No caso dos dados configurados para o teste de hipótese para o nível educacional atual, o valor da significância do Teste de Levene é 0,316 , ou seja, maior que 0,05 , mantendo a hipótese nula de que as variâncias são iguais, conforme o Quadro 11.

Para realizar o teste, a codificação consistiu em considerar como número $1 \mathrm{os}$ estudantes que possuíam somente a formação de Ensino Médio (representado por 118 indivíduos) e como número 2 os estudantes que já cursavam qualquer tipo de graduação (77 estudantes). É importante ressaltar que o questionário apresentava a opção Ensino Médio; Graduação e Pós-Graduação. Portanto, participaram estudantes à nível de Pós-Graduação também, mas como o número de 7 indivíduos era muito pequeno em relação aos outros dois grupos, optou-se por realizar o teste de hipótese somente entre estudantes egressos do Ensino Médio e cursistas ou diplomados de Graduação. Isso explica a discrepância entre o número total de analisados neste item em relação aos demais deste artigo.

Quadro 12: Saída do software estatístico para Teste U

Ranks

\begin{tabular}{|c|c|c|c|c|c|}
\hline \multicolumn{3}{|c|}{ Nivel educacional atual } & $\mathrm{N}$ & Mean Rank & Sum of Ranks \\
\hline \multirow[t]{3}{*}{ Acertos } & \multicolumn{2}{|l|}{1} & 118 & 92,02 & 10858,00 \\
\hline & \multicolumn{2}{|l|}{2} & 77 & 107,17 & 8252,00 \\
\hline & \multicolumn{2}{|l|}{ Total } & 195 & & \\
\hline \multicolumn{3}{|c|}{ Test Statistics $^{a}$} & & & \\
\hline & & Acertos & & & \\
\hline Mann-V & hitney U & 3837,000 & & & \\
\hline Wilcoxo & $\mathrm{n} W$ & 10858,000 & & & \\
\hline z & & $-1,860$ & & & \\
\hline Asymp. & Sig. (2-tailed) &, 063 & & & \\
\hline \multicolumn{3}{|c|}{$\begin{array}{l}\text { a. Grouping Variable: } \\
\text { Nivel_educacional_atual }\end{array}$} & & & \\
\hline
\end{tabular}

Hypothesis Test Summary

\begin{tabular}{|c|c|c|c|c|}
\hline & Null Hypothesis & Test & Sig. & Decision \\
\hline & $\begin{array}{l}\text { The distribution of Acertos is the } \\
\text { same across categories of } \\
\text { Nivel_educacional_atual. }\end{array}$ & $\begin{array}{l}\text { Independent- } \\
\text { Samples } \\
\text { Mann- } \\
\text { Whitney U } \\
\text { Test }\end{array}$ &, 063 & $\begin{array}{l}\text { Retain the } \\
\text { null } \\
\text { hypothesis. }\end{array}$ \\
\hline
\end{tabular}

Asymptotic significances are displayed. The significance level is ,05.

Fonte: autores. 
Conforme observado no Quadro 12, o nível de significância bilateral observado é de 0,063 , ou seja, p-valor maior que 0,05 , não permite rejeitar a hipótese nula na qual afirma que as médias das duas amostras são as mesmas para os dois grupos. Embora os estudantes cursistas ou diplomados da Graduação tenham obtido um desempenho ligeiramente superior que o outro grupo, essa diferença não foi significativa para a distribuição de acertos entre os grupos.

Dessa forma, pode-se afirmar que não há diferença entre os questionários respondidos por estudantes que já ingressaram na graduação em comparação aos estudantes que possuem somente a formação do Ensino Médio.

A partir da análise do Quadro 13 é possível notar algumas diferenças entre o desempenho dos três grupos. Entre elas, o fato de que conforme a formação educacional aumenta, o desempenho nas medidas de tendência central demonstra superioridade sobre os outros, principalmente se atentar às medidas de média e moda, mesmo que esse desempenho não caracterize uma diferença significativa entre a distribuição de médias dos grupos.

Quadro 13: Medidas de tendência central e dispersão para nível escolar atual

\section{Statistics}

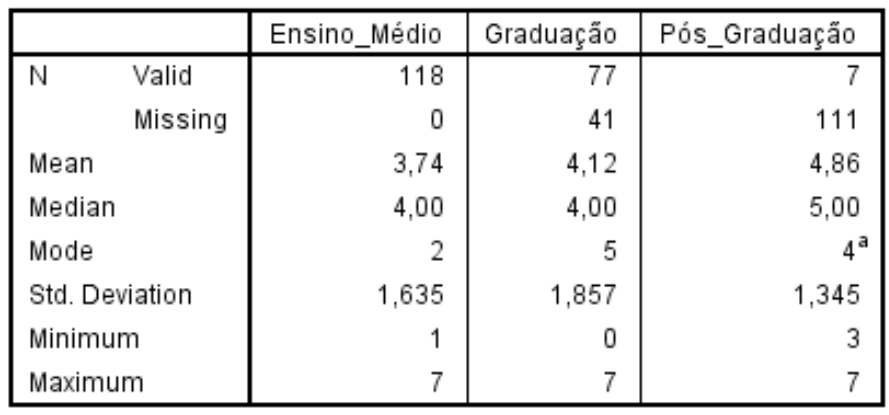

a. Multiple modes exist. The smallest value is shown

Fonte: autores.

Observa-se que as distribuições de acertos entre os grupos podem ser consideradas homogêneas, corroborando com o resultado do teste de hipótese de não se rejeitar a hipótese nula, ou seja, para estes 202 indivíduos investigados, possuir um maior grau de nível escolar não foi diretamente proporcional ao desempenho dos mesmos no questionário de pesquisa. 


\section{Teste de hipótese para faixa etária}

Esse teste teve como objetivo notar se houve diferença de desempenho entre estudantes mais novos e os mais velhos. Para tal, considerou-se a faixa etária delimitada como pré-requisito ( 18 a 30 anos) e dividiu-se os estudantes em dois grupos: os mais novos e os mais velhos. O grupo 1, estudantes mais novos, compreendeu participantes com idades de 18 a 23 anos e o grupo 2, estudantes mais velhos, obteve o restante das idades até o ponto de corte de 30 anos, ou seja, de 24 a 30 anos. Inicialmente realizou-se o teste para observar a homogeneidade de variâncias.

Quadro 14: Saída do software estatístico para Teste de Levene

\section{Test of Homogeneity of Variances}

\begin{tabular}{|c|c|c|c|}
\hline $\begin{array}{l}\text { Levene } \\
\text { Statistic }\end{array}$ & df1 & $\mathrm{df} 2$ & Sig. \\
\hline 888 & 1 & 200 & 347 \\
\hline
\end{tabular}

Fonte: autores.

No caso dos dados configurados para o teste, o valor da significância é 0,347 , sendo maior que 0,05 , mantêm a hipótese nula de que as variâncias são homogêneas, como mostrado no Quadro 14. 
Quadro 15: Saída do software estatístico para Teste U

Ranks

\begin{tabular}{|rl|r|r|r|}
\hline & Faixa de idade & \multicolumn{1}{|c|}{ N } & Mean Rank & Sum of Ranks \\
\hline Acertos & 1 & 117 & 100,48 & 11756,50 \\
& 2 & 85 & 102,90 & 8746,50 \\
& Total & 202 & & \\
\hline
\end{tabular}

Test Statistics ${ }^{\text {a }}$

\begin{tabular}{|l|r|}
\hline & \multicolumn{1}{|c|}{ Acertos } \\
\hline Mann-Whitney U & 4853,500 \\
Wilcoxon W & 11756,500 \\
Z &,- 294 \\
Asymp. Sig. (2-tailed) &, 768 \\
\hline
\end{tabular}

a. Grouping Variable:

Faixa_de_idade

\begin{tabular}{|c|c|c|c|c|}
\hline \multicolumn{5}{|c|}{ Hypothesis Test Summary } \\
\hline & Null Hypothesis & Test & Sig. & Decision \\
\hline 1 & $\begin{array}{l}\text { The distribution of Acertos is the } \\
\text { same across categories of } \\
\text { Faixa_de_idade. }\end{array}$ & $\begin{array}{l}\text { Independent- } \\
\text { Samples } \\
\text { Mann- } \\
\text { Whitney U } \\
\text { Test }\end{array}$ &, 768 & $\begin{array}{l}\text { Retain the } \\
\text { null } \\
\text { hypothesis. }\end{array}$ \\
\hline
\end{tabular}

Asymptotic significances are displayed. The significance level is ,05.

Fonte: autores.

Nota-se que o ranking de médias apresentou resultados praticamente iguais para os dois grupos, corroborando para que as distribuições não apresentassem nenhuma diferença entre elas, ou seja, a diferença de idade não acarreta automaticamente experiência e maior capacidade de relacionar conceitos físicos com o cotidiano de trânsito.

O nível de significância bilateral observado é de 0,768 , ou seja, p-valor maior que 0,05 , não permite rejeitar a hipótese nula na qual afirma que a distribuição de acertos entre os dois grupos é igual.

Assim, se pode afirmar que não há diferença entre os questionários respondidos por estudantes de faixas etárias diferentes. Desse modo, os dois grupos possuem estatisticamente a mesma distribuição de acertos, isto é, o fator "diferença de idade" não afetou o desempenho de um indivíduo para relacionar a Física com o trânsito.

A seguir é possível observar com detalhes a estatística descritiva para esses dois grupos. 
Quadro 16: Medidas de tendência central e dispersão para diferentes idades

Statistics

\begin{tabular}{|c|c|c|c|}
\hline & & $\begin{array}{c}\text { De_18_à_23 } \\
\text { _anos }\end{array}$ & $\begin{array}{c}\text { De_24_à_30 } \\
\text { _anos }\end{array}$ \\
\hline \multirow[t]{2}{*}{$N$} & Valid & 117 & 85 \\
\hline & Missing & 0 & 32 \\
\hline \multicolumn{2}{|c|}{ Mean } & 3,90 & 3,95 \\
\hline \multicolumn{2}{|c|}{ Median } & 4,00 & 4,00 \\
\hline \multicolumn{2}{|c|}{ Mode } & 2 & 4 \\
\hline \multicolumn{2}{|c|}{ Std. Deviation } & 1,749 & 1,704 \\
\hline \multicolumn{2}{|c|}{ Minimum } & 0 & 0 \\
\hline \multicolumn{2}{|c|}{ Maximum } & 7 & 7 \\
\hline
\end{tabular}

Fonte: autores.

Observa-se que a maior parte dos estudantes eram pertencentes ao grupo 1 , indivíduos mais novos, entre 18 e 23 anos, com 117 pessoas e o grupo 2 foi composto por 85 estudantes. As medidas de tendência central Média e Mediana podem ser consideradas iguais para os dois grupos, deixando somente a Moda como diferente entre eles ( 2 acertos para o grupo 1 e 4 acertos para o grupo 2).

De forma similar, as análises das frequências de acertos para os dois grupos demonstram que as diferenças entre as distribuições não foram significativas para se postular qualquer conclusão de diferença entre os desempenhos dos estudantes.

\section{Discussões}

Tendo em vista que o estudo da Física engloba a interpretação e explicação da natureza, é numerosa a quantidade de fenômenos aplicados ao trânsito que se pode compreender a partir do conhecimento da Física escolar.

Todo professor dispõe intuitivamente de ferramentas das quais se utiliza para desenvolver suas aulas, visando o melhor desempenho do ensino e da aprendizagem, constituindo o seu peculiar método. Sem insinuar qualquer juízo de valor em especifico a qualquer metodologia que os professores venham a adotar, é necessário considerar que algumas ferramentas são mais efetivas do que outras no quesito de despertar o interesse, motivação e consequente aprendizagem dos estudantes. 
Outro fato reside na importância de valorizar os saberes que os estudantes trazem para a sala de aula, sendo esses os elos entre o conteúdo e a vida desses estudantes. Acima de tudo, de acordo com a Teoria da Aprendizagem Significativa, esses elos podem ser pontos de ancoragem entre um conhecimento novo e um conceito já existente na sua estrutura cognitiva (AUSUBEL, 2003). É fundamental considerar tais saberes, pois são constituídos durante suas diversas interações na sociedade e em reflexões particulares, compondo um mundo de certezas internas, que se forem errôneas, dificilmente serão desconstruídas contra vontade.

Para Toti e Pierson (2010), o cotidiano é percebido como uma possibilidade de chegar-se aos conhecimentos prévios dos estudantes, podendo ser, dessa forma, um organizador de referencial comum para se observar os elementos necessários à construção das estruturas de pensamento desejáveis no Ensino de Física.

Desse modo, defende-se que essas concepções não deveriam ser ignoradas pelos docentes, pois podem influenciar na forma com que novos conhecimentos serão interpretados, considerados e, por sua vez, legitimados ou não. Ou seja, influencia diretamente no processo de aprendizagem do estudante.

Valorizar seus saberes e compreender a dinâmica da comunidade local em que esses estudantes estão inseridos, ajudaria o docente a planejar com maior efetividade suas abordagens e a munir-se de possibilidades para aliar um novo conhecimento a esse cotidiano, a fim de buscar um sentido de maior significância para o assunto que o estudante está conhecendo.

Dentro dessa realidade, a contextualização aliada à problematização consiste em uma dessas ferramentas que o professor poderia utilizar, na medida do possível, como instrumento facilitador dessa construção de significados, conforme salienta Chagas (2014):

A importância do ensino de Física contextualizado ao automóvel não se restringe à compreensão do seu funcionamento, mas também à necessidade de uma maior conscientização por parte dos motoristas, para os perigos que o mau uso desta ferramenta oferece aos seus ocupantes, pois os acidentes de trânsito têm ceifado muitas vidas. (CHAGAS, 2014, p.25).

Nesse sentido, conceitos de Física e seus fenômenos aplicados a situações observadas no trânsito, formam uma listagem extensa de associações que podem ser utilizadas nessas construções, possibilitando essa abordagem em tópicos de praticamente as três séries do Ensino Médio, englobando assim, diversos conteúdos da disciplina de Física. 
Essa aliança também proporciona, segundo Brust (2013), uma combinação na qual poderá melhorar duas coisas que precisam de atenção no cotidiano: o Ensino de Física que será levado para a vida do aluno e a prevenção de acidentes de trânsito.

Para Oliveira (2011) o respeito às leis de trânsito poderia ter como essência o respeito às leis da Física e não somente o temor em evitar uma multa de trânsito:

Ao se aplicar o ensino de física na formação do cidadão, pode-se ter a física no trânsito, onde o indivíduo seria capaz de respeitar os limites de velocidade não só pelo fato da multa por excesso de velocidade, mas também pelo fato de saber que dependendo da condição da via e da velocidade que está imprimindo em seu veículo, ele necessita de uma determinada distância para conseguir pará-lo (OLIVEIRA, 2011, p. 24).

Acredita-se que tais relações possam proporcionar eficácia na aprendizagem e na formação cidadã devido ao confronto de realidade, aliado a um novo conhecimento estudado dentro de tal contexto, que poderá despertar melhores compreensões do fenômeno estudado. De acordo com os dados quantitativos sobre acidentes e mortalidades no trânsito (BRASIL, 2018), deve-se considerar que a violência no trânsito é um assunto que merece atenção da escola, uma vez que esta busca também a construção de valores e formação da cidadania. Muitos desses acidentes são causados por imprudências e negligências do condutor, e dentre os muitos motivos que os levam a realizá-las, a falta de informação e conhecimento das causas e efeitos de suas ações é um deles.

Dentro desses conhecimentos estão os de cunho científico, os quais defendemos que, se compreendidos de forma efetiva, podem atuar na conscientização e prevenção de complicações maiores, como mortes no trânsito, por exemplo.

Nesse sentido, a Escola e o Ensino de Física ganham notório espaço, possuindo o embasamento teórico para atuar na explicação de muitos desses fenômenos percebidos no cotidiano do trânsito, sendo dessa forma, um contexto de importante relevância a ser abordado nas aulas de Física, além de estarem de acordo com as orientações dos documentos do Ministério da Educação (BRASIL,1996, 2000, 2019).

Com os índices de acertos e erros por participante, aplicou-se o Teste U de Mann-Whitney em 5 hipóteses sobre as suas distribuições:

1- é independente do gênero;

2- é independente do tipo de estabelecimento onde o Ensino Médio foi cursado;

3- é independente da experiência prévia na direção de veículos;

4- é independente do nível de escolaridade atual;

5- é independente da faixa etária. 
Estas afirmações são denominadas hipóteses nulas e, após a aplicações dos testes, verificou-se que as hipóteses 2 e 3 foram rejeitadas, sugerindo que existe uma correspondência entre o tipo de estabelecimento de ensino de origem dos entrevistados, bem como a experiência prévia com a condução de veículos, com o número de acertos no instrumento de avaliação.

Com base no observado por esses resultados, verificou-se que eles corroboram para a concepção de que a formação básica e as experiências de cada indivíduo podem colaborar para que eles consigam observar o mundo de forma mais crítica, em especial o mundo da Física e do trânsito juntos.

Podemos considerar que aqueles que já haviam dirigido antes do curso no CFC, podem ter adquirido capacidades intuitivas de compreender os fenômenos Físicos através de suas vivências, dando-lhes maior capacidade de aliar a teoria e a prática, como se pode notar pelo desempenho superior dos que já haviam dirigido antes da autoescola.

Quanto ao fator "tipo de estabelecimento de ensino", o melhor resultado dos oriundos de escolas particulares replica os números divulgados anualmente para o Exame Nacional do Ensino Médio. Não queremos aqui fazer a comparação entre os sistemas de ensino, mas aproveitamos a dependência apontada pelos testes de hipótese para endereçar alguns questionamentos.

Em primeiro lugar, tem-se a questão do currículo escolar, o qual alguns conteúdos não conseguem ser aprofundados em função do calendário. Além disso, pouco espaço é dedicado para a formação do professor para inovar em sua prática docente. Isso significa que o professor, apesar de sua liberdade para planejar sua estratégia de ensino, não consegue tempo ou espaço para incluir uma nova abordagem, ou uma metodologia diferenciada, que permitiria um ensino mais contextualizado e próximo do estudante. Talvez nem mesmo se tenha condições para conhecer de forma mais aprofundada a realidade local da escola e dos alunos, em função do tempo escasso.

Aliás, este afastamento da ciência ensinada na escola para o cotidiano expõe uma segunda questão: os alunos não conseguem dar significado aos conhecimentos apreendidos na sala de aula. Isso dificulta o seu aprendizado, exceto se considerarmos a validade da Aprendizagem Mecânica dos conceitos científicos. Este também é um ponto que pode explicar a melhor média de egressos de escolas particulares.

O último ponto a ser endereçado é a valorização do professor e seu papel na formação do cidadão-aluno. Devemos ter presente que a escola, seja ela pública ou 
privada, deve proporcionar um espaço para valorização da prática do professor, permitindo a sua inovação. Ao falarmos em inovação, não estamos apenas nos remetendo aos recursos tecnológicos e digitais, mas principalmente a novas metodologias de ensino, modificando a rotina de sala de aula.

Sobre o cotidiano do trânsito, tais resultados convergem para o que os autores da área, como Urruth (2014), Back (2013) e Brust (2013) também discorrem em relação à importância de haver um ensino contínuo da educação para o trânsito durante todos os anos da Educação Básica, abordando tal temática de forma transversal, interdisciplinar, ou ainda, de forma disciplinar, reforçando a oportunidade da Física em articular tais conhecimentos em situações aplicadas, salientando assim, o papel da contextualização no Ensino de Física, conforme defendem os autores Abeid e Tort (2014), Chagas (2014) e Silveira (2011).

Muitas estratégias de ensino ditas "inovadoras", baseadas em conhecimentos da psicologia cognitiva, ou que buscam envolver o estudante ativamente na sala de aula são realizadas, testadas e apresentadas no mundo acadêmico do Ensino de Física. Porém, a aprendizagem não acontece somente na escola, assim como não se dá do dia para a noite. Aprender exige certo intervalo de tempo para que a retenção possa acontecer e posteriormente ser observada de forma direta ou indireta, reforçando assim, o viés da investigação socializada neste manuscrito, o qual entrevistou egressos da escola, de diferentes idades, que concluíram o Ensino Médio em diferentes intervalos de tempo.

\section{Considerações finais}

Neste artigo, apresentamos os resultados quantitativos de uma pesquisa que buscou investigar se os estudantes de autoescola estabelecem relações entre conteúdos de Física escolar e o cotidiano do trânsito, a fim de notar se a proposta de ensino orientada pelos documentos oficiais do Ministério da Educação, de ensinar para a vida e formar um cidadão preparado para compreender de forma significativa o cotidiano, está surtindo resultados relevantes posteriores à formação do indivíduo na escola.

Os resultados apresentados relacionaram, através de Testes de Hipótese, o índice de acertos individual com características específicas do participante, como idade, gênero, escolaridade e experiência como condutor de veículos. 
As análises realizadas não esgotam o tema, pelo contrário, demonstram que investigar a compreensão do conhecimento escolar na perspectiva de egressos do Ensino Médio é um meio relevante de notar como os saberes escolares são retidos e utilizados pelos indivíduos durante situações do cotidiano.

Como perspectiva para estudos futuros, sugere-se analisar não apenas a retenção conceitual do egresso, mas sim o uso do seu conhecimento para interpretar situações que envolvem resolução de problemas, pois acreditamos que os conhecimentos intrínsecos e não somente os extrínsecos, também devem ser considerados quando se busca mensurar quais os saberes que podem influenciar na tomada de decisão de uma pessoa.

Deseja-se, por fim, que na continuidade desta investigação, sejam criadas ferramentas que possibilitem mensurar não somente se houve ou não influência do ensino no desempenho, mas o quanto a escola influencia neste fenômeno. Em outras palavras, verificar se a correlação percebida nestes resultados, possui de fato, uma relação causal.

\section{The use of hypothesis tests to assess the existence of difference in the performance of graduates of high school in the task of relating physics with the daily traffic}

\section{Abstract}

The results of a research that investigated if graduates of high school relate to school physics with the daily traffic. To this end, a questionnaire was applied with questions of physics applied to this context, and subsequently, hypothesis tests were performed in order to verify whether groups with opposite characteristics of this same sample presented performances Statistically different from each other. Hypotheses of equal averages were tested between gender, age, school reality, experience with vehicles and current educational level, using the Mann-Whitney $U$ test. It was noted that participants who completed high school in private schools, as well as those who had already directed to the moment of the research, obtained statistically higher performances than the opposite group. These findings corroborate the conception that the quality of the teaching, the consideration of the students 'previous knowledge and the experiences experienced by each individual, can be factors of impact on learning, enhancing greater retention Of physical concepts in graduates of basic education and the possibility of developing a critical view of their everyday life, basic precepts of a scientific literacy.

Keywords: Physics teaching. Physics applied to traffic. Quantitative research. Scientific literacy. 
ABEID, Leonardo; TORT, Alexandre. As forças de atrito e os freios ABS. Revista Brasileira de Ensino de Física, v. 36, n. 2, p. 2306-1-2306-7, 2014.

AUSUBEL, David Paul. Aquisição e retenção de conhecimentos: uma perspectiva cognitiva. Lisboa: Plátano, v. 1, 2003.

BACK, Susan. Física e Segurança no Trânsito: Uma Proposta Didática por uma Professora Iniciante. 159p. Mestrado em Educação em Ciências. Dissertação. Universidade Federal de Santa Maria, Santa Maria, 2013.

BRASIL, Lei de diretrizes e bases da educação nacional. Brasília: MEC, 1996.

PCN do Ensino Médio: Parâmetros Curriculares Nacionais. Ciências da Natureza. Matemática e suas Tecnologias, Ministério da Educação, Secretaria de Educação Básica, 2000.

, Relatório anual do plano nacional de redução de Mortes e lesões no trânsito. Ministério das Cidades. 2018.

Ministério da Educação. Base Nacional Comum Curricular. $2^{\underline{a}}$ ed. revista. Disponível em: <http://basenacionalcomum.mec.gov.br/documentos/bncc 2versao.revista.pdf>. Acesso em: 05 abril, 2019.

BRUST, Alexandre. Física Aplicada Nas Situações Do Trânsito. 78p. Mestrado em Ensino de Física e Matemática. Dissertação. Centro Universitário Franciscano, Santa Maria. 2013.

CHAGAS, Caio. A Física no ensino médio através do estudo de fenômenos físicos em um automóvel. 231p. Mestrado em Ensino de Ciências e Matemática. Dissertação. Universidade Federal do Ceará, Fortaleza. 2014.

COSTA, Sergio Francisco. Estatística aplicada à pesquisa em educação. Brasília: Plano Editora, 2006.

HAIR, Joseph; BLACK, William; BABIN, Barry; ANDERSON, Rolph; TATHAM, Ronald. Análise Multivariada de Dados. 6ª ed. Porto Alegre: Bookman Editora 2006.

HILL, Manuela Magalhães; HILL, Andrew. Investigação por questionário. Lisboa: Sílabo, 2005.

HURD, Paul DeHart. Science literacy: Its meaning for Ameriucan Schools. Educational Leadership, v. 16, p. 13-16, 1958.

KIRSTEN, José; RABAHY, Wilson. Estatística aplicada às ciências humanas e ao turismo. São Paulo: Saraiva, 2006.

NEGRINI NETO, Oswaldo; KLEINUBING, Rodrigo. Dinâmica dos acidentes de trânsito. 4 ed. Campinas: Millennium Editora, 2012.

NOBRE, Érica. Elaboração e validação de questionário para descrever o estilo de vida de mães de pré-escolares. 202p. Faculdade de Medicina da Universidade de São Paulo. Dissertação. São Paulo, 2012.

OLIVEIRA, Kemuel Costa. A utilidade do Ensino de Física. 78p. Trabalho de Conclusão de Curso. Universidade Federal de Rondônia. Rondônia, 2011.

PASQUALI, Luiz; PRIMI, Ricardo. Fundamentos da Teoria da Resposta ao Item - TRI. Avaliação Psicológica, 2, 99-110, 2003. 
PEREIRA, Alexandre. SPSS-Guia prático de utilização-Análise de Dados para Ciências Sociais e Psicologia. 6 ${ }^{\text {a }}$ Ed, Lisboa: Edições Sílabo, 2006.

PIRES, Ana. Probabilidades e estatísticas. 2000. Disponível em: <https://www.math.tecnico. ulisboa.pt/ apires/MaterialPE/AulaTCap8C.pdf>. Acesso: maio 2019

SILVEIRA, Fernando Lang da. Um interessante e educativo problema de cinemática elementar aplicada ao trânsito de veículos automotores - a diferença entre $60 \mathrm{~km} / \mathrm{h}$ e $65 \mathrm{~km} / \mathrm{h}$. Caderno Brasileiro de Ensino de Física, v. 28, n. 2, p. 468-475, ago. 2011.

TOTI, Frederico; PIERSON, Alice. Elementos para uma aproximação entre a Física no ensino médio e o cotidiano de trabalho de estudantes trabalhadores. Investigações em Ensino de Ciências, v. 15, n. 3, p. 527-552, 2010.

URRUTH, Henrique. Física e segurança no trânsito: um curso de Física e educação para o trânsito para jovens e adultos. 201p. Mestrado em Ensino de Física. Dissertação. Universidade Federal do Rio Grande do Sul, Porto Alegre. 2014.

VIZZOTTO, Patrick Alves; MACKEDANZ, Luiz Fernando. Física aplicada ao trânsito: processo de validação de um questionário para coleta de dados. Revista Brasileira de Ensino de Física, v. 41, n. 3, p. e20180256, 2019.

\section{ANEXO}

Questionário utilizado na pesquisa - Link: https://encurtador.com.br/dlJMY 